\title{
Endovascular repair of the thoracic aorta necessitating anchoring of the stent graft across the arch vessels
}

\author{
Maria Schoder, MD, ${ }^{a}$ Martin Grabenwöger, MD, ${ }^{\mathrm{b}}$ Thomas Hölzenbein, MD, ${ }^{\mathrm{c}}$ Manfred Cejna, MD, ${ }^{a}$ Marek P. Ehrlich, MD, \\ Thomas Rand, MD, ${ }^{a}$ Alfred Stadler, MD, ${ }^{a}$ Martin Czerny, MD, ${ }^{b}$ Christoph M. Domenig, MD, ${ }^{c}$ Christian Loewe, MD, \\ and Johannes Lammer, MD
}

Supplemental material is available online.
Objective: The purpose of the study was to determine technical and clinical results in endovascular repair of thoracic aortic diseases necessitating stent-graft anchoring across the arch vessels.

Methods: The causes for endovascular treatment in 58 patients (aged 20 to 84 years) were aneurysms $(\mathrm{n}=32)$, acute type A $(\mathrm{n}=2)$ and type B dissections $(\mathrm{n}=17)$, posttraumatic transections $(\mathrm{n}=4)$, iatrogenic dissection $(\mathrm{n}=1)$, and penetrating ulcers with an intramural hematoma $(\mathrm{n}=2)$. Surgical revascularization of arch vessels was performed in 26 patients before stent-graft implantation. Intentional overstenting of the left subclavian artery resulted in complete occlusion in 8 and was partial in 24 patients.

Results: The 30-day mortality rate was $3.4 \%$. Overall, 19 major postprocedural complications occurred in 14 (24\%) patients. Among patients with left subclavian artery occlusion, 2 patients had major (1 paraplegia, 1 critical arm ischemia), and 3 minor ( 2 temporary vertebrobasilary symptoms, 1 transient arm claudication) complications. Fourteen (25\%) patients had an early endoleak, of whom 5 were treated successfully with a secondary endovascular procedure, 2 necessitated open surgical conversion, and 7 were treated conservatively, with spontaneous sealing of the endoleak in 3. In 53 (91\%) in whom computed tomographic follow-up was longer than 3 months (mean, 30.1 months, range, 3 to 85), the aortic diameter along the stented segment decreased in 24 , was stable in 19 , and increased in 10 patients.

Conclusion: Fixation of the stent graft in the aortic arch can expand the applicability of endovascular repair. Intentional overstenting should be performed with caution to avoid ischemic problems after complete occlusion of left subclavian artery.

\footnotetext{
From the Department of Angiography and Interventional Radiology, ${ }^{\text {a }}$ Cardio-Thoracic Surgery, ${ }^{\mathrm{b}}$ and Vascular Surgery, ${ }^{\mathrm{c}}$ University of Vienna Medical, Vienna, Austria.

Received for publication March 2, 2005; revisions received Nov 2, 2005; accepted for publication Nov 8, 2005.

Address for reprints: Maria Schoder, MD, Department of Angiography and Interventional Radiology, University of Vienna Medical School, Waehringer Guertel 1820, A-1090, Vienna, Austria (E-mail: maria. schoder@meduniwien.ac.at).

J Thorac Cardiovasc Surg 2006;131:380-7

$0022-5223 / \$ 32.00$

Copyright () 2006 by The American Association for Thoracic Surgery

doi:10.1016/j.jtcvs.2005.11.009
}

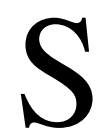
ince the first endovascular application of a self-fixing synthetic prosthesis for the treatment of a traumatic thoracic aortic aneurysm by Volodos and associates $^{1}$ in 1988 , this less invasive procedure became an alternative modality to open surgical repair in a selected population of patients. Several studies suggest that this endovascular treatment modality may reduce postoperative morbidity and mortality rates, as well as hospital stay. ${ }^{2,3}$ However, successful stent-graft placement requires a satisfactory landing zone of at least $15 \mathrm{~mm}$ in length. ${ }^{4}$ Although various pathologies begin just distal to the left subclavian artery (LSA) or include the distal arch, innovative techniques have extended endovascular treatment options. Overstenting of the left subclavian artery has been performed without acute adverse events to elongate the proximal landing zone..$^{5-7}$ However, delayed onset of vertebrobasilary insufficiency and arm ischemia has been reported. ${ }^{8,9}$ Bypass surgery or transposition of aortic arch vessels before stent-graft repair is sometimes mandatory to preserve blood flow or to prevent type II endoleaks. ${ }^{10,11}$ Alternatively, initial clinical experiences with branched stent grafts have been reported. ${ }^{12,13}$ 


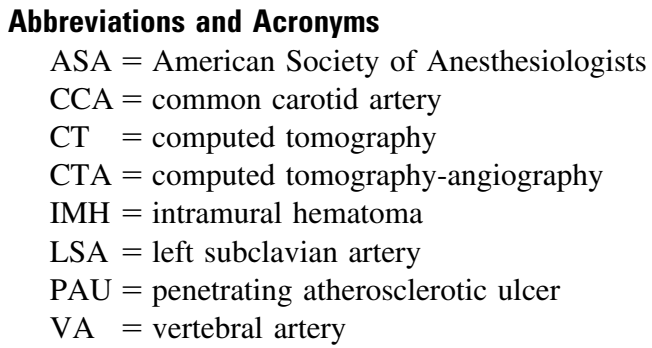

This report presents the results of our experience with treatment of thoracic aortic diseases necessitating stent-graft placement across the origin of arch vessels. Evaluation was focused on management of aortic arch vessels and clinical consequences. Furthermore, frequency of endoleaks related to the landing zone and change of aortic size in the stented segment were evaluated.

\section{Material and Methods \\ Patient Evaluation}

Between November 1996 and April 2004, at total of 107 patients were treated with endovascular repair. Fifty-eight (54\%) patients who required anchoring of the stent graft at the origin of arch vessels were included in this study. There were 13 women and 45 men with a mean age of 61.8 years (range, 20 to 84 years). The associated comorbidities are listed in Table 1. Fixation in the aortic arch was performed in 32 patients with aneurysms (25 atherosclerotic aneurysms, 4 chronic posttraumatic aneurysms, and 3 aneurysms related to previous surgery for coarctation). Furthermore, there were 2 patients with acute type A and 17 patients with acute type B dissections. One patient had an iatrogenic dissection, 4 patients had a posttraumatic transection, and 2 patients had penetrating atherosclerotic ulcers (PAUs) and an intramural hematoma (IMH).

Of the 58 patients, 19 (32.8\%) had associated complications. Eleven of the $19(57.9 \%)$ required emergency stent grafting for treatment of aortic rupture $(n=1)$, contained rupture $(n=6)$, or compromised aortic branches $(n=4)$. The remaining 8 patients had complications that required urgent but not emergency treatment.

Indication for stent grafting in aneurysms $(n=32)$. Of 25 patients with atherosclerotic aneurysms, $3(12 \%)$ presented with a contained rupture necessitating emergency stent grafting. In the remaining patients, an American Society of Anesthesiology (ASA) class of at least III was the indication for elective endovascular repair. Furthermore, 5 patients had a history of cardiac $(n=1)$ or thoracic aortic surgery $(n=4)$.

Indication for stent grafting in dissections $(n=20)$. In patients with a type A dissection $(n=2)$, additional stent grafting was required after surgical replacement of the ascending aorta because of a compromised iliac artery in 1 patient. To prevent further dilatation of the thoracic aortic diameter, we placed an additional stent graft in the second patient who presented with an aortic diameter of more than $40 \mathrm{~mm}$, flow within the false lumen due to an intimal tear close to the left subclavian artery, and compression of the true lumen.
TABLE 1. Comorbidities in 58 patients with thoracic aortic aneurysm or dissection who were treated by endovascular repair

\begin{tabular}{lcc}
\hline Associated medical problems & No. of patients & Percent \\
\hline Hypertension & 43 & 74 \\
Coronary artery disease & 7 & 12 \\
Previous cardiac infarction & 3 & 5 \\
COPD & 6 & 10 \\
Renal impairment & 15 & 26 \\
Mild-moderate & 11 & 19 \\
Severe & 4 & 7 \\
Diabetes mellitus & 12 & 21 \\
One occluded internal carotid artery & 2 & 3 \\
Previous stroke & 2 & 3 \\
Malignancy & 4 & 7 \\
Previous cardiac or aortic surgery & 7 & 12 \\
ASA scores & & \\
$\quad$ Class III & 42 & 72 \\
Class IV & 8 & 14 \\
Class V & 8 & 14
\end{tabular}

COPD, Chronic obstructive pulmonary disease. Mild-moderate renal failure $=$ serum creatinine concentration $1.4-2.5 \mathrm{mg} / \mathrm{dL}$; severe renal failure $=$ serum creatinine concentration $>2.5 \mathrm{mg} / \mathrm{dL}$.

Of patients with an acute type B dissection $(\mathrm{n}=17), 13(76.5 \%)$ were treated because of one or more associated complications (Table 2). In 4 asymptomatic acute type B dissections with an aortic diameter of more than $40 \mathrm{~mm}$, a patent false lumen, and marked compression of the true lumen, stent grafting was performed to prevent progression of dissection and aneurysmal degeneration.

One patient with an iatrogenic dissection was treated to prevent progression of dissection.

Indication for stent grafting in other thoracic aortic diseases $(n=6)$. Patients with a posttraumatic transection $(n=4)$ presented with multiple serious injuries. Additionally, one patient had a contained rupture with a mediastinal hematoma. Among patients with a PAU/IMH $(n=2), 1$ patient who had poorly manageable hypertension was treated to prevent deterioration and the other was treated for a contained rupture.

In our institution, endovascular repair of thoracic aortic diseases has been considered as an alternative treatment to surgical repair in high-risk patients since 1996. Written informed consent was obtained from all conscious patients. In emergency situations and with unconscious patients, endovascular treatment was an interdisciplinary decision.

Patients were selected for endovascular repair on the basis of contrast-enhanced computed tomography (CT)-angiography (CTA) using either a single-detector (Somatom Plus 4; Siemens, Erlangen, Germany) or a multidetector (Somatome Volume Zoom; Siemens) scanner. CT scanning ranged from the supra-aortic vessels to the common femoral arteries. Three-dimensional reconstruction (multiplanar reconstruction, curved planar reconstruction, maximum-intensity projection) were processed from each CT scan.

In 9 patients with atherosclerotic aneurysms, the origin of the LSA was in the aneurysm. The remaining patients had a distance 
TABLE 2. Associated complications of acute type B dissection in 13 symptomatic patients

\begin{tabular}{|c|c|c|c|c|c|c|c|c|c|c|c|c|c|}
\hline \multirow[b]{2}{*}{ Complications } & \multicolumn{13}{|c|}{ Patient } \\
\hline & 1 & 2 & 3 & 4 & 5 & 6 & 7 & 8 & 9 & 10 & 11 & 12 & 13 \\
\hline Rupture & Y & & & & & & & & & & & & \\
\hline Contained rupture & & & Y & & & & & & & & & & \\
\hline Compromised visceral arteries & Y & & & $\mathrm{Y}$ & $\mathrm{Y}$ & $\mathrm{Y}$ & $\mathrm{Y}$ & & & & & & \\
\hline Compromised iliac arteries & & & Y & & & & & Y & $\mathrm{Y}$ & & & & \\
\hline Refractory hypertension & & $\mathrm{Y}$ & & & $\mathrm{Y}$ & & & Y & & $\mathrm{Y}$ & $\mathrm{Y}$ & & \\
\hline Pleural effusion & & Y & Y & & & $\mathrm{Y}$ & & Y & & $\mathrm{Y}$ & $\mathrm{Y}$ & $\mathrm{Y}$ & \\
\hline Rapid progression of diameter & & Y & & & & & & & & & & $\mathrm{Y}$ & $\mathrm{Y}$ \\
\hline Continuing pain & & $\mathrm{Y}$ & & & & & & & & $\mathrm{Y}$ & & & \\
\hline
\end{tabular}

$Y$, Presence of clinical symptoms and radiologic findings.

between the LSA and the aneurysm or the entry tear into the dissection of less than $15 \mathrm{~mm}$ (ranging from 0 to $14 \mathrm{~mm}$ ).

According to the proposed classification of landing zones by Mitchell and coworkers, ${ }^{14}$ required proximal stent-graft attachments were classified within the 3 zones: zone 0 (includes the origin of brachiocephalic trunk), zone 1 (includes the origin of the left common carotid artery [CCA]), and zone 2 (includes the origin of LSA).

To avoid ischemic adverse events, primary surgical revascularization of the LSA was performed in patients with a dominant left vertebral artery (VA), with a marked stenosis of the origin of the right VA, or an occluded internal carotid artery. Intentional overstenting of the LSA without previous revascularization was performed in patients who had a good and an equal caliber of both VAs. Blood flow within the CCAs was preserved by either transposition or bypass surgery.

\section{Endovascular Prosthesis and Procedure}

In 30 patients a Talent endoprosthesis (Medtronic, Sunrise, Fla) was implanted. The Thoracic Excluder (W. L. Gore \& Associates, Inc, Flagstaff, Ariz) was used in 27 patients and an Endofit endoprosthesis (Endomed, Phoenix, Ariz) in 1 patient. The diameter of the stent graft was calculated from the largest diameter of the proximal or distal neck and an oversizing factor of $10 \%$ to $20 \%$ was added.

Procedures were performed in the angiography suite, which is equipped with digital subtraction angiography (Multistar T.O.P.; Siemens). Treatment was performed with the patients under general or epidural anesthesia. After surgical cutdown of the femoral or iliac artery $(n=52)$ or the infrarenal aorta $(n=6)$, an antibiotic prophylaxis and $5000 \mathrm{IU}$ of heparin sodium were administered intravenously. To perform angiograms immediately before stentgraft release, we positioned a pigtail catheter in the ascending aorta via a percutaneous left or right brachial access. The stent-graft system was inserted over a super stiff guide wire (Back-up Meier, Boston Scientific Corp., Natick, Mass) and deployed using an overlay imaging technique in at least $40^{\circ}$ left anterior oblique view. Systolic pressure was pharmacologically lowered to $60 \mathrm{~mm} \mathrm{Hg}$ during prosthesis deployment. To improve expansion and the friction seal, we used an appropriate-sized latex balloon (Thoracic Excluder balloon catheter; W. L. Gore \& Associates; Reliant balloon, Medtronic, Sunrise, Fla) for modeling the proximal and distal end of the stent graft to the aortic wall in all aneurysms. To avoid creation of additional entry tears in type B-dissections, we preferred to leave the attachment zones without balloon inflation. Finally, completion angiograms were performed.

\section{Follow-up}

Routinely, CTA was performed before hospital discharge, at 3, 6, and 12 months, and annually thereafter. In patients with an aortic dissection, 1 acquisition, including intrathoracic arch vessels and iliac arteries, was performed. In patients with aneurysms, additional late acquisitions with a 30-second interscan delay were made to rule out small endoleaks. In patients with impaired renal function, magnetic resonance imaging was conducted for follow-up.

Follow-up measurements of the maximum aortic diameter at the stented segment were performed perpendicular to the axis of the vessel.

\section{Statistical Analysis}

A minimum follow-up of 3 months was required to evaluate changes of the aortic size. To overcome the variability in measurements, we considered a change of diameter to be significant when there was a difference of $4 \mathrm{~mm}$ or more as compared to the first postprocedural CTA, as previously described. ${ }^{15}$ Continuous variables are expressed as means \pm standard deviation.

For statistical analysis concerning the frequency of proximal attachment endoleaks after stent-graft repair of aneurysms, patients were divided into group I (anchoring zone 0 and 1) and group II (anchoring zone 2). Differences were tested for significance using the $\chi^{2}$ test for proportions. Statistical analysis was performed using a statistical software package (SPSS Rel. 13; SPSS Inc, Chicago, Ill).

\section{Results}

\section{Technical Results}

Before stent graft implantation, a bypass was created to 1 (LSA, $\mathrm{n}=1$ ) or 2 (brachiocephalic trunk and left CCA, $\mathrm{n}=$ 1 , and left CCA and LSA, $n=2$ ) arch vessels. Before endovascular repair, the LSA was transposed solely $(\mathrm{n}=$ 17) or in combination with transposition of the left CCA $(\mathrm{n}=5)$. In patients without previous revascularization of the LSA, the origin was completely occluded in 8 and partially overstented in 24 patients. 
Stent-graft anchoring in zone 0 was necessary in 9 patients. All had an atherosclerotic aneurysm involving the distal arch. After surgical revascularization, the origin of the left CCA $(n=6)$, the LSA $(n=6)$, and the brachiocephalic trunk $(\mathrm{n}=1)$ was overstented. In 3 patients the LSA was covered without revascularization. Three patients had a left CCA origin at the brachiocephalic trunk. In 13 patients the bare springs (Talent endoprosthesis) or flairs (Excluder endoprosthesis) were positioned in zone 1 (7 aneurysms, 5 dissections, 1 posttraumatic transection; Figure E1). The origin of the left CCA $(n=2)$ and the LSA $(n=8)$ was overstented after surgical revascularization in 8 patients. In another 5 patients the LSA was covered completely $(\mathrm{n}=2)$ or partially $(\mathrm{n}=3)$ without prior revascularization. In 36 patients the fixation of the stent graft was in zone 2 (16 aneurysms, 15 dissections, 3 posttraumatic transections, 2 PAU/IMH). The LSA was overstented after surgical revascularization in 11 patients. Complete LSA overstenting $(\mathrm{n}=3)$ and partial LSA overstenting $(\mathrm{n}=21)$ were performed without surgical revascularization in this group. In 1 patient only the bare springs were anchored over the LSA origin.

Deployment of stent grafts was technically successful in all patients. However, due to distal retraction of the stent graft into the aneurysm sac during deployment or dilation or to inadequate sealing between segments, immediate intraprocedural overstenting was required in 7 patients.

In aortic dissections closure of the entry tear and expansion of the true lumen after stent-graft deployment resulted in satisfactory reperfusion of compromised visceral or iliac arteries in 7 of 9 patients. A residual obstruction of the superior mesenteric artery in 1 patient, and of the iliac artery in a second patient, was additionally treated with placement of an uncovered stent into the true lumen of these vessels.

\section{Clinical Outcome and Survival}

Two (7.7\%) patients had complications after surgical revascularization of arch vessels before the endovascular procedure. One patient had Horner's syndrome, and the second patient had hoarseness due to recurrent laryngeal nerve injury that resolved over time.

After the stent-graft procedure, 19 major postprocedural complications occurred in 14 (24\%) patients and led to death in 2, resulting in a perioperative mortality rate of $3.4 \%$. One patient with type B dissection died of pericardial tamponade after retrograde type A dissection on day 9 after endovascular repair. The second patient with a ruptured type B dissection and primarily successful occlusion of the entry tear died because of rerupture during surgical evacuation of the hemothorax. A retrograde type A dissection occurred in another 2 patients with an atherosclerotic aneurysm in 1 and an acute type B dissection in the other. Both patients were treated successfully by surgical repair.
Further major complications were hemorrhage at the access site $(\mathrm{n}=2)$, requiring surgical revision in both patients. One of these had hypovolemic shock, which was accompanied by prolonged intubation and hemodialysis. Prolonged intubation was necessary in a second patient because of lung atelectasis and in a third patient with severe gastrointestinal bleeding due to heparin-induced thrombocytopenia who also required hemodialysis. Three (5.2\%) patients without occlusion of the LSA had a stroke with transient neurologic deficits. Two patients had a right-sided cerebral infarction. The third patient whose LSA was revascularized by a carotid-subclavian bypass had an infarction in the territory of the posterior cerebral artery on both sides after LSA overstenting. Spinal cord ischemia with temporary paraparesis occurred in 2 patients with incomplete overstenting of the LSA, and in whom the stent graft was fixed distally at the level of the seventh and ninth thoracolumbar vertebrae (Th7 and Th9). A permanent paralysis occurred in 1 patient whose LSA was overstented and the device covered Th8 distally. Critical arm ischemia developed in 1 patient after complete occlusion of the LSA, necessitating transposition of the LSA.

Regarding patients with complete occlusion of LSA, 5 of $8(63 \%)$ presented with adverse events. Two patients had major periprocedural complications (1 paraplegia, 1 critical arm ischemia). Minor complications occurred in 3 patients (2 incomplete subclavian steal syndromes with temporary dizzy spells, 1 with temporary arm claudication).

Among patients with partial covering of the LSA, 1 (4\%) of 24 patients had transient attacks of dizziness.

\section{CTA Follow-up in Thoracic Aortic Aneurysms}

At the first postprocedural CTA 12 (37.5\%) of 32 patients presented with an endoleak. Type of endoleaks, management, and CT follow-up data are listed in Table 3. In 7 (21.9\%) patients incomplete sealing at the proximal attachment zone (type Ia endoleak) occurred. Comparing the frequency of type Ia endoleaks in aneurysms, there was a higher rate in group I (including zone 0 and 1 ) than in group II (zone $2 ; P=.344)$. Five (15.6\%) patients had an incomplete sealing between segments (type III endoleak), leading to disconnection of segments in 2. In 1 of these patients, endovascular treatment failed due to severe kinking of the thoracic aorta. Because of comorbidities, this patient was refused for surgical conversion. The second patient refused any further treatment.

An early reperfusion of the aneurysm sac from side branches (type II endoleak) was detected before hospital discharge in 2 patients. The type II endoleak, caused by intercostal arteries, remained in 1 patient who also had a type III endoleak, which was treated successfully by overstenting. In the second patient, who had a type II endoleak through thyrocervical branches, enlargement of the aneu- 
rysm sac necessitated surgical conversion after embolization of these branches failed.

Two outpatients were lost to follow-up CT examinations. During a mean observation period of $36.4 \pm 26.7$ months (range, 3 to 85 months) a late endoleak was detected in 3 (10\%) of 30 patients. A type II endoleak occurred in 1 patient after overstenting of the LSA and required LSA transposition. In 1 patient with a sealed primary endoleak (patient 8), who was treated with an Excluder endoprosthesis, a small midgraft endoleak developed (related to a fabric tear), which was detected at the 5-year CT follow-up. After an initial decrease of the aneurysm sac within the first 4 years, this endoleak caused enlargement of the aneurysm to the original size. Because of an inappropriate access site for endovascular repair and his high surgical risk, this patient is under observation without further intervention. In the third patient, an endoleak developed at the distal attachment site due to aneurysm growth caused by a primary type II endoleak (patient no. 10). The patient was successfully treated by embolization of intercostal arteries and distal overstenting.

During the follow-up period, 22 (73.3\%) of patients were without a visible endoleak at any time or a sealed primary endoleak. In these patients, mean decrease of the aneurysm size was $15 \pm 8 \mathrm{~mm}$ (range, 5 to $27 \mathrm{~mm}$ ) in 10 patients. The aneurysm size remained stable in 10 patients, but 2 patients showed a substantial increase ( 41 and $15 \mathrm{~mm}$ ) of the aneurysms sac (type V endoleak-endotension). With CT-guided puncture of the aneurysm sac in 1 of the latter patients, straw-colored fluid was aspirated. Overstenting of the prosthesis was performed in both patients. During a 2-month follow-up period, the aneurysm size in both patients decreased by $14 \mathrm{~mm}$ and $3 \mathrm{~mm}$, respectively.

\section{CTA Follow-up of Aortic Dissections, PAU/IMHs, and Posttraumatic Transections}

At the first postprocedural CTA, $2(8.3 \%)$ of 24 patients presented with an early endoleak. In 1 patient with an iatrogenic dissection, the entry tear next to the LSA could be closed by proximal overstenting in a second procedure. In the second patient with a traumatic transection, a fabric tear in the expanded polytetrafluoroethylene (ePTFE) membrane of the Excluder was identified, which was also treated successfully by overstenting.

One outpatient was lost to CTA follow-up examinations. Overall, $23(88.5 \%)$ patients had a mean CT follow-up of $21.9 \pm 15.3$ months (range, 4.6 to 52.7 ).

In patients with a type A or B dissection, the false lumen along the stented thoracic aortic segment was thrombosed in all but $1(94 \%)$. Expansion of the stent graft resulted in a mean diameter increase of the true lumen of $19 \pm 7.7 \mathrm{~mm}$, and the false lumen resolved completely in $10(59 \%)$ patients. The false lumen distal to the stent graft thrombosed in $10(59 \%)$ of 17 patients in the thoracic segment and in 3 (20\%) of 15 patients in the abdominal aortic segment.
The intramural hematoma in both patients with penetrating ulcers resolved completely during the observation period.

In traumatic dissections, the aortic diameter decreased in 1 patent and was stable in 3 .

\section{Discussion}

Over the past 10 years, endovascular stent-graft repair of atherosclerotic thoracic aortic aneurysms ${ }^{5,16}$ and dissections, including atherosclerotic penetrating ulcers ${ }^{17,18}$ and traumatic $^{7,10}$ and type B dissections, ${ }^{6,19}$ has proven to be a promising, less invasive treatment modality than open surgical repair. However, in aortic abnormalities that are close to the LSA or include the distal arch, one of the most difficult and challenging aspects is the absence of an adequate proximal anchoring zone for secure fixation of the device. Different strategies for lengthening of the proximal landing zone are reported in the literature and were followed in our patients.

In a few series, simple overstenting of the LSA ${ }^{6,20-22}$ is reported as a feasible and well-tolerated procedure for fixation of the stent graft. In the study group of Görich and coworkers $^{21}$ with incomplete overstenting of LSA in 4 and complete occlusion of the LSA in 19 patients, 22 patients had at least a 1-month follow-up. From those, 3 (13.6\%) patients reported ischemic arm symptoms but none of the patients had persistent signs of vertebrobasilary insufficiency. On the other hand, in the series of Tiesenhausen and associates, ${ }^{9} 3(37.5 \%)$ of 8 patients with partial or complete occlusion of LSA had vertebrobasilar symptoms.

In our study group, only $2(25 \%)$ of 8 patients with complete occlusion of the overstented LSA were without symptoms at any time. Secondary transposition of LSA was necessary in 2 patients, 1 for treatment of critical arm ischemia and 1 , an endoleak.

As known from the literature, most patients with atherosclerotic subclavian artery stenosis or occlusions are clinically asymptomatic. ${ }^{23,24}$ However, slow progression of subclavian stenosis promotes collateral vessel development from the thyrocervical and external carotid arteries. ${ }^{25}$ In acute LSA occlusion lack of collateral pathways might result in ischemic symptoms in a considerable number of patients as shown in our study. As reported in the literature, ${ }^{26}$ occlusion of 1 VA caused vertebrobasilary ischemia resulting in cerebellar infarction in $2.7 \%$. This ischemic event might be related to the ability of the contralateral VA to supply blood to the posterior circulation. Furthermore, bilateral VA occlusion, which can be also simulated by overstenting of the LSA and an additional severely stenotic or hypoplastic right VA, caused irreversible neurologic problems in $23 \%$ of patients. In case of atherosclerotic diseased supra-aortic vessels, the presence of multilevel disease involving both the CCAs and VAs was reported in $87 \% .^{23}$ Therefore, to avoid infarction, a noncompromised 
blood supply between the anterior and posterior circulation via the posterior communicating artery seems to be essential. ${ }^{26,27}$ To minimize the risk for ischemic disorders, one should evaluate the CCA and VA, as well as the circle of Willis, before intentional LSA occlusion. Moreover, anatomic variants, such as origin of the left VA at the arch or a nonexisting fusion of the VAs to the basilary artery, do not allow LSA occlusion without previous revascularization. To minimize disadvantages after LSA overstenting, we changed our CTA protocol recently and now start the evaluation at the level of the circle of Willis. Another aspect of preserving optimized blood flow within the LSA is to provide sufficient flow into the left internal thoracic artery to enable bypass surgery in patients with a coronary artery disease.

Another indication for transposition of the LSA or LSAto-left CCA bypass surgery followed by ligation of the LSA is to avoid retrograde perfusion of the aneurysm sack in distal arch aneurysms, as happened in one of our patients, or to avoid retrograde perfusion of the false lumen in dissections as reported by Tiesenhausen and colleagues. ${ }^{9}$

If complete overstenting of the LSA is necessary and there is any concern for potential ischemic events, it is our intention to revascularize the LSA in advance rather than in a secondary procedure. Surgical complications of LSA transposition in our series were transient symptoms of Horner syndrome and hoarseness in $2(7.1 \%)$ of 28 patients. Low morbidity rates in subclavian artery revascularizations are also reported in the literature. ${ }^{23,24}$ Alternatively, to maintain arch vessel perfusion, branched stent grafts have been devised in a few studies. ${ }^{12,13}$ In the series of Inoue and associates, ${ }^{12}$ one third of patients had major complications, and primary exclusion of the aneurysm was achieved in $60 \%$ only. This result clearly demonstrates the difficulty and complexity of endovascular repair of distal arch aneurysms.
In the present study, the 30-day mortality was $3.4 \%$. Of particular concern was the death due to retrograde type A dissection, which happened on day 9 after stent-graft repair. Overall, 3 of our patients who were treated either with the Gore or the Talent endoprosthesis had retrograde dissections. Therefore, we believe that the proximal bare springs (Talent endoprosthesis) are not the only reason for wall damage, as suspected by Orend and colleagues. ${ }^{7}$ The limited flexibility of the devices might produce forced wall stress at the outer curvature leading to intimal injuries as reported in previous series. ${ }^{28,29}$

Paraparesis and paraplegia occurred in $5.1 \%$ of our patients, which is higher than in other reported studies. ${ }^{7,30}$ However, spinal cord ischemia only occurred after treatment of acute dissections. One of these patients additionally had an intentional overstenting of the LSA. Therefore, LSA occlusion with interruption of collateral pathways to the spinal artery might lead to a higher risk for paraplegia. None of our patients with atherosclerotic aneurysms had ischemic spinal cord symptoms, leading to the assumption that collateral vessel formation between intercostals are stimulated by slow progression of atherosclerotic changes.

The rate of primary endoleaks after endovascular repair of variant thoracic aortic lesions was reported to be $11 \%$ to $20 \% .^{3,5,7,11}$ In our patient group with fixation of the device in the arch, the first CTA showed a primary endoleak in 12 $(37.5 \%)$ of 32 patients treated for aneurysms and in 2 $(8.3 \%)$ of 24 surviving patients with dissections. However, because of the ongoing tendency of the stent graft to expand, small endoleaks may seal spontaneously. Thus, delayed sealing occurred in 3 of 14 patients, and in 2 the endoleak decreased under observation. Overall, during the follow-up period, an additional endovascular procedure was performed successfully in $5(71 \%)$ of 7 patients with per-

TABLE 3. Management and CT follow-up of primary endoleaks in 12 patients treated for aneurysms

\begin{tabular}{|c|c|c|c|c|c|c|c|c|}
\hline Pts & $\begin{array}{l}\text { Anchoring } \\
\text { zone }\end{array}$ & $\begin{array}{c}\text { Arch vessel } \\
\text { revascularization }\end{array}$ & $\begin{array}{c}\text { Primary } \\
\text { endoleak }\end{array}$ & Reintervention & $\begin{array}{l}\text { CT follow-up } \\
\text { (d) }\end{array}$ & $\begin{array}{l}\text { Change of } \\
\text { aneurysm } \\
\text { size (mm) }\end{array}$ & \multicolumn{2}{|c|}{ CT follow-up of primary endoleaks } \\
\hline 1 & 0 & Bypass to LCCA + LSA & III & No & 2102 & +34 & III & Disconnection of segments \\
\hline 2 & 0 & LSAT & III & Ballooning & 10 & No & No & Sealed \\
\hline 3 & 0 & LSAT + LCCAT & la & No & 99 & -5 & la & Endoleak decreased \\
\hline 4 & 0 & LSAT + LCCAT & Ia, III & No & 143 & No & la & la decreased, III sealed \\
\hline 5 & 0 & LSAT + LCCAT & la & No & 193 & No & No & Sealed \\
\hline 6 & 1 & LSAT & III & No & 469 & +19 & III & Disconnection of segments \\
\hline 7 & 1 & LSACO & la & Ballooning & 582 & -14 & No & Sealed \\
\hline 8 & 1 & LSAT + LCCAT & la & No & 670 & $+16^{*}$ & No & Sealed* \\
\hline 9 & 2 & LSAPO & la & Overstenting & 2128 & +20 & la & Surgical conversion \\
\hline 10 & 2 & LSAPO & II, III & Overstenting & 1382 & $+23 \dagger$ & II & III sealedt \\
\hline 11 & 2 & LSAT & la & No & 113 & No & No & Sealed \\
\hline 12 & 2 & LSAPO & II & Embolization & 445 & +16 & II & Surgical conversion \\
\hline
\end{tabular}

Pts, patients; $L C C A$, left common carotid artery; $L S A$, left subclavian artery; LSAT, LSA transposition; LCCAT, LCCA transposition; LSACO, LSA complete overstenting; LSAPO, LSA partial overstenting. *Patient had a late type III endoleak. †Patient had a late type lb endoleak. 
sistent primary endoleaks. Two patients required surgical conversion. Two patients with a type III endoleak received no further treatment.

Comparison of the frequency of type Ia endoleaks in aneurysms according to zone groups demonstrated a higher tendency in those patients with anchoring of the device in the proximal versus the distal arch. Therefore, despite innovative techniques to lengthen the proximal attachment zone, the inability of currently available stent grafts to hug the curved aortic arch in all instances still remains the reason for primary incomplete sealing of aneurysms in a considerable number of patients.

In 2 patients who had no visible endoleaks but a substantial increase of the aneurysm size, endotension was assumed. Supported by reports in the literature describing transudation of fluid through PTFE grafts, ${ }^{31,32}$ porosity of the e-PTFE membrane of the Excluder endoprosthesis was thought to cause a perigraft seroma. Moreover, decrease of the aneurysm sac in both patients after overstenting confirmed our primary hypothesis of graft-porosity.

In conclusion, ancillary techniques in management of aortic arch vessels can expand the applicability of endovascular repair in thoracic aortic aneurysms and dissections. However, available devices in the study period were not flexible enough to hug the aortic arch in all patients.

Intentional overstenting of the LSA resulted in ischemic disorders in a considerable number of our patients. Therefore, to reduce unforeseen ischemic problems, accurate evaluation of supra-aortic arteries is mandatory. Surgical revascularization of the LSA is recommended in patients in whom any concern for potential ischemic events exists. Table 3.

\section{References}

1. Volodos NL, Karpovich IP, Shekhanin VE, Troian VI, Iakovenko LF. A case of distant transfemoral endoprosthesis of the thoracic artery using a self-fixing synthetic prosthesis in traumatic aneurysm. Grudn Khir. 1988;6:84-6.

2. Najibi S, Terramani TT, Weiss VJ, Mc Donald MJ, Lin PH, Redd DC, et al. Endoluminal versus open treatment of descending thoracic aortic aneurysms. J Vasc Surg. 2002;36:732-7.

3. Taylor PR, Gaines PA, McGuinness CL, Cleveland TJ, Beard JD, Cooper G, et al. Thoracic aortic stent grafts-early experience from two centres using commercially available devices. Eur J Vasc Endovasc Surg. 2001;22:70-6.

4. Dake MD. Endovascular stent-graft management of thoracic aortic disease. Eur J Radiol. 2001;39:42-9.

5. Burks JA, Faries PL, Gravereaux EC, Hollier LH, Marin ML. Endovascular repair of thoracic aortic aneurysm: stent-graft fixation across the aortic arch vessels. Ann Vasc Surg. 2002;16:24-8.

6. Nienaber CA, Ince H, Weber F, Rehders T, Petzsch M, Meinertz T, et al. Emergency stent-graft placement in thoracic aortic dissection and evolving rupture. J Card Surg. 2003;18:464-70.

7. Orend KH, Scharrer-Pamler R, Kapfer X, Kotsis T, Görich J, Sunder-Plassmann L. Endovascular treatment in diseases of the descending thoracic aorta: 6-year results of a single center. J Vasc Surg. 2003;37:91-9.
8. Dake MD, Miller DC, Mitchell RS, Semba CP, Moore KA, Sakai T. The "first generation" of endovascular stent grafts for patients with aneurysms of the descending thoracic aorta. J Thorac Cardiovasc Surg. 1998;116:689-704.

9. Tiesenhausen K, Hausegger KA, Oberwalder P, Mahla E, Tomka M, Allmayer T, et al. Left subclavian artery management in endovascular repair of thoracic aortic aneurysms and aortic dissections. J Card Surg. 2003; 18:429-35.

10. Kato N, Dake MD, Miller DC, Semba CP, Semba CP, Mitchell RS, et al. Traumatic aortic aneurysms: treatment with endovascular stentgrafts. Radiology. 1997;205:657-62.

11. Criado FJ, Clark NS, Barnatan MF. Stent graft repair in the aortic arch and descending thoracic aorta: a 4-year experience. J Vasc Surg. 2002; 36:1121-8.

12. Inoue $\mathrm{K}$, Hosokawa $\mathrm{H}$, Iwase $\mathrm{T}$, Sato M, Yoshida $\mathrm{Y}$, Ueno K, et al. Aortic arch reconstruction by transluminally placed endovascular branched stent graft. Circulation 1999;100(suppl II):316-21.

13. Chuter TA, Schneider DB, Reilly LM, Lobo EP, Messina LM. Modular branched stent graft for endovascular repair of aortic arch aneurysm and dissection. J Vasc Surg. 2003;38:859-63.

14. Mitchell RS, Ishimaru S, Ehrlich MP, Iwase T, Lauterjung L, Shimono $\mathrm{T}$, et al. First international summit on thoracic aortic endografting: roundtable on thoracic aortic dissection as an indication for endografting. J Endovasc Ther. 2002;9:II-98-105.

15. Schoder M, Cartes-Zumelzu F, Grabenwöger M, Cejna M, Funovics M, Krenn CG, et al. Elective endovascular stent-graft repair of atherosclerotic thoracic aortic aneurysms: clinical results and midterm follow-up. AJR Am J Roentgenol. 2003;180:709-15.

16. Greenberg R, Resch T, Nyman U, Lindh M, Brunkwall J, Brunkwall $\mathrm{P}$, et al. Endovascular repair of descending thoracic aortic aneurysms: an early experience with intermediate-term follow-up. J Vasc Surg. 2000;31:147-56.

17. Schoder M, Grabenwöger M, Hölzenbein T, Domanovits H, Fleischmann D, Wolf F, et al. Endovascular stent-graft repair of complicated penetrating atherosclerotic ulcers of the descending thoracic aorta. $J$ Vasc Surg. 2002;36:720-6.

18. Demers P, Miller C, Mitchell RS, Kee ST, Chagonjian L, Dake MD. Stent-graft repair of penetrating atherosclerotic ulcers in the descending thoracic aorta: mid-term results. Ann Thorac Surg. 2004; 77:81-6.

19. Lonn L, Delle M, Falkenberg M, Lepore V, Klingenstierna M, Radberg G, et al. Endovascular treatment of type B thoracic aortic dissections. J Card Surg. 2003;18:539-44.

20. Sunder-Plassmann L, Scharrer-Pamler R, Liewald F, Kapfer X, Görich J, Orend KH. Endovascular exclusion of thoracic aortic aneurysms: mid-term results of elective treatment and in contained rupture. $J$ Card Surg. 2003;18:367-74.

21. Görich J, Asquan Y, Seifarth H, Kramer S, Kapfer X, Orend KH, et al. Initial experience with intentional stent-graft coverage of the subclavian artery during endovascular thoracic aortic repairs. $J$ Endovasc Ther. 2002;9:II39-43.

22. Hausegger KA, Oberwalder P, Tiesenhausen K, Tauss J, Stanger O, Schedlbauer $\mathrm{P}$, et al. Intentional left subclavian artery occlusion by thoracic aortic stent-grafts without surgical transposition. $J$ Endovasc Ther. 2001;8:472-6.

23. Cinà CS, Safar HA, Laganà A, Arena G, Clase CM. Subclavian carotid transposition and bypass grafting: consecutive cohort study and systematic review. J Vasc Surg. 2002;35:422-9.

24. Sterpetti AV, Schultz RD, Farina C, Feldhaus RJ. Subclavian artery revascularization: a comparison between carotid-subclavian artery bypass and subclavian-carotid transposition. Surgery. 1989;106: 624-32.

25. Ackermann H, Diener HC, Seboldt H, Huth C. Ultrasonographic follow-up of subclavian stenosis and occlusion: natural history and surgical treatment. Stroke. 1988;19:431-5.

26. Steinberg GK, Drake CG, Peerless SJ. Deliberate basilar or vertebral artery occlusion in the treatment of intracranial aneurysms. $J$ Neurosurg. 1993;79:161-73. 
27. Schomer DF, Marks MP, Steinberg GK, Johnstone IM, Boothroyd DB, Ross MR, et al. The anatomy of the posterior communicating artery as a risk factor for ischemic cerebral infarction. $N$ Engl J Med. 1994;330: 1565-70.

28. Fattori R, Napoli G, Lovato L, Grazia C, Piva T, Rocchi G, et al. Descending thoracic aortic diseases: stent-graft repair. Radiology. 2003;229:176-83.

29. Totaro M, Miraldi F, Fanelli F, Mazzesi G. Emergency surgery for retrograde extension of type B dissection after endovascular stent graft repair. Eur J Cardiothorac Surg. 2001;20:1057-8.
30. Mitchell RS, Miller C, Dake MD, Semba CP, Moore KA, Sakai T. Thoracic aortic aneurysm repair with an endovascular stent graft: the "first generation." Ann Thorac Surg. 1999;67:1971-4.

31. Cho J-S, Dillavou ED, Rhee RY, Makaroun MS. Late abdominal aortic aneurysm enlargement after endovascular repair with the Excluder device. J Vasc Surg. 2004;39:1236-42.

32. Thoo CHC, Bourke BM, May J. Symptomatic sac enlargement and rupture due to seroma after open abdominal aortic aneurysm repair with polytetrafluoroethylene graft: implications for endovascular repair and endotension. J Vasc Surg. 2004;40:1089-94. 

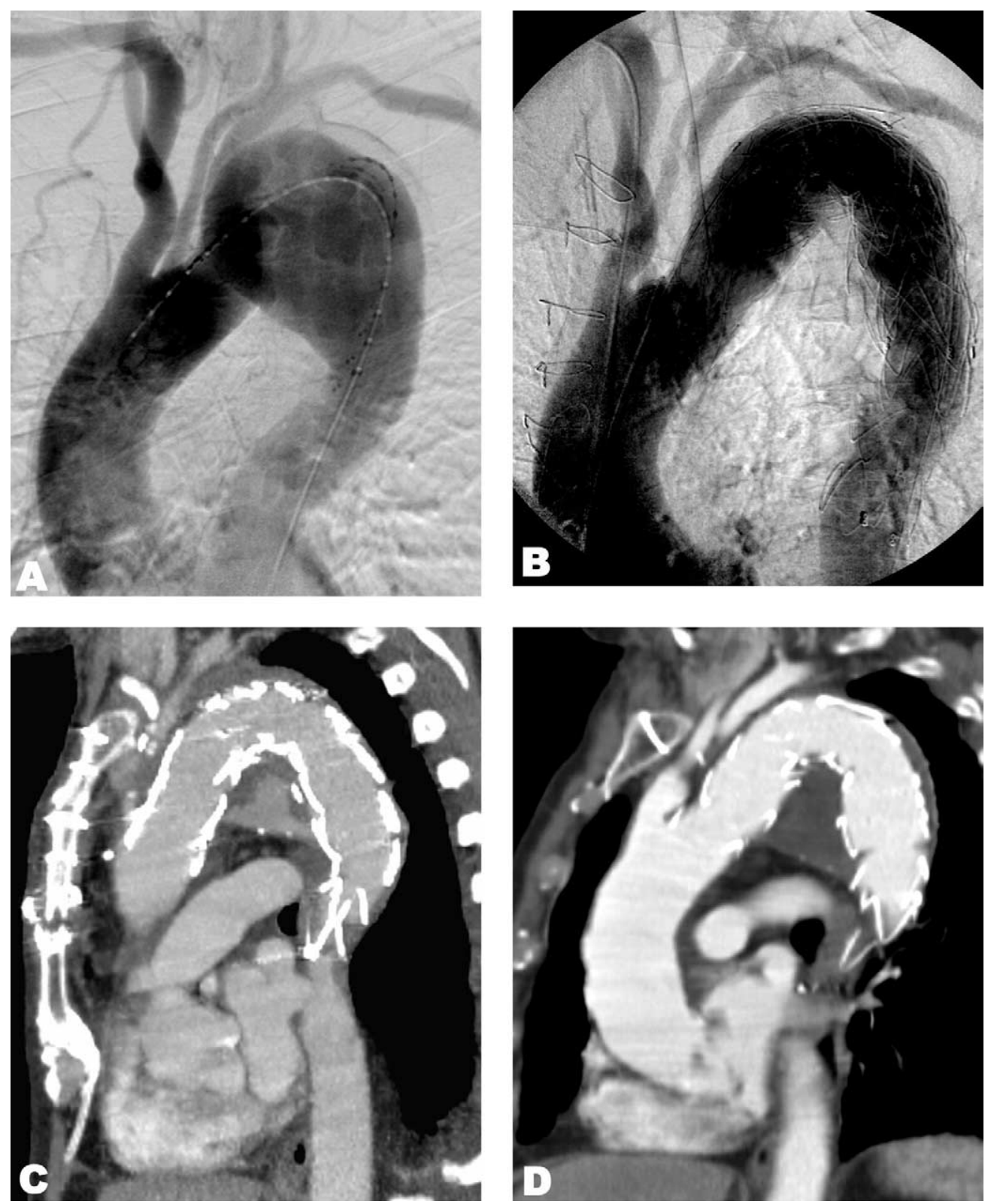

Figure E1. A, Angiogram with a calibrated pigtail-catheter shows origin of the LSA from the aneurysm and a $1 \mathrm{~cm}$ proximal neck to the left carotid artery. B, After transposition of the LSA to the left CCA and the left CCA to the brachiocephalic trunk, the aneurysm was treated with 3 Talent endoprosthesis (zone 1). C, First CT follow-up shows a type la endoleak at the lesser curvature. D, The 3-month CT follow-up demonstrated spontaneous sealing of the endoleak. 